-Journal Publications • Research Consultancy

\title{
COMPARISON STUDY OF WEAR RESISTANCE IN RECIPROCATING COMPRESSORS FOR SMALL COOLING MACHINES
}

\section{JEHAD S. RADAIDEH}

Department of Mechanical Engineering, Al-Huson University College Al-Balqa Applied University, Irbid-Jordan

In this paper, we analyzed the corrosion resistance indicators for $(H R)$ category compressors in comparison of other types of open compressors indicators (open type) and half open (semi-hermetic sealed) that used for the same purpose. An experimental test for corrosion resistance components of these compressors was used. These tests were conducted on the various compressors in similar conditions which allowed achieving this comparison.

The different effects of wear resistance on compressor components in terms of design parameters and operating parameters were studied, such as the Frequency of the shaft, number of cylinders, the type and location of the shaft, the specific pressure, the sliding speed of the compressor, type of main bearing, the initial roughness of surfaces friction, the initial clearance in the fits, the type of refrigerant and lubricating oil.

HR type compressors generally possess a higher degree of resistance to wear, which provides operational life about 37,000 hours. However, in these compressors, they cannot meet equal wear resistance in Plug-arm and rotating column. The increase in wear resistance in friction surfaces allows an increase in the operational life of the compressor. KEYWORDS: Reciprocating Compressor, Wear Resistance \& Refrigerators
\end{abstract}

Received: Sep 02, 2018; Accepted: Oct 24, 2018; Published: Jan 08, 2019; Paper Id.: IJMPERDFEB201929

\section{INTRODUCTION}

A decisive criterion for the production stage of new and further developed products is given by verifying the reliability during design, whereby predetermined reliability requirements must be met by examinations and tests. The investigation of wear problems in reciprocating compressors is usually done through the standard wear tests defined for the compressor approval cycle. These tests are effective to However, indicate if the wear level in each bearing is acceptable or not. Wear tests sometimes do not allow identifying the specific circumstances in which lubrication breakdown occur. Apart from the influence of the number of units tested, the assurance of the results essentially depends on the correlation between the loads under test conditions and actual operating conditions. As hermetic compressors must be suitable for various applications of different requirements the selection of the testing conditions is of great importance. In preparation for the production of large quantities of reciprocating sealed compressors (high-speed hermetic reciprocating compressors) (HR) assigned to work in commercial refrigeration equipment, food preservation, and milk refrigeration units, Particular attention is given to raise the thermal specifications related to energy, as well as reliability or credibility as well as longevity. These compressors are not subject to regular maintenance for the duration of any work life - for that issue, the resistance to the erosion of compressor components is gaining particular importance. 
Compressor component failures can be divided into two major categories, environmental and mechanical [1]. Environmental causes are those elements in the valve environment that can lead to valve failures, such as corrosive contaminants, foreign material, liquid slugs, or improper lubrication. Environmental failures can sometimes be prevented by the proper choice of valve material and conditioning of the gas stream (filtration, separation, etc.). Several past studies have been conducted to understand valve failures and prolong valve life in order to improve compressor performance. In 2003, engineers at El Paso Corporation investigated six different compressor valves from five manufacturers in order to determine valve efficiency, reliability, and cost of operation [2]. The six-month investigation found that valve efficiencies were directly related to compressor pressure ratios, where inefficiency was attributed to valve leakage at low compression ratios.

Zhang et. all [3] use metallographic structure analysis of crosshead material to analyze the C102B reciprocating piston compressor to find the reason of fracture because of the complexity of exact dynamics analysis. Based on the above study, the results have an important significance for judging the reason of crosshead failure. As a mean of avoiding the contact between the sliding parts which may result in excessive friction and wear, it is essential that the lubricant oil is delivered instantaneously to the radial and thrust bearings and to the piston-cylinder gap. In addition to the more obvious role of lubrication, the oil performs many other tasks in the compressor. Among these ones may cite cooling, sealing, protecting against corrosion, acting as a hydraulic fluid, reducing the noise level and maintaining low equalizing pressures during the off-cycle [4]. Lubrication efficiency between the piston and cylinder of reciprocating compressors is evaluated through electrical instrumentation [5]. This technique is based on the measurement of the electrical resistance between the two components when partially insulated by the lubrication film during operation. An electric potential difference with is imposed by a proper circuit, and the measured voltage decreases the increase of the total area of metallic contact between the surfaces of the components. The theoretical and experimental evaluation of the performance and reliability of the hermetic reciprocating compressor for HC600a, recently studied by Kim et. all [6]. The thermodynamic and dynamic simulation has been conducted to investigate the performance variations of the hermetic reciprocating compressor with HC600a as a refrigerant. A new compressor for $\mathrm{HC} 6(\mathrm{X}) \mathrm{a}$ has been developed according to the simulation data, and a variety of tests has been conducted to obtain the desired reliability.

This study presents an experimental procedure to test the corrosion resistance components of (HR) category compressors in comparison with other types of open compressors and half open (semi-hermetic sealed) that used for the same purposes. The comparison is made between some standards on cross-sections and levels of maximum corrosion surfaces friction in periods of startup and corrosion geostationary values of the average velocity of wear and average velocity of clearance growth.

\section{CASE STUDY}

To analyze the wear resistance for (HR) compressors and compared with the wear resistance for other types of open compressors and half-open type (semi-hermetic sealed) that used for the same purposes, experimental verification is necessary. To do this comparison, the results of experimental tests for wear resistance of all fit components of these compressors need to be analyzed. Table 1. List the technical characteristics and design features of the tested compressor. These tests were conducted on the various compressors in similar conditions which allowed achieving this analytical comparison. Table 2. Show the test conditions for all tested compressors. 
Table 1: Technical Characteristics and Design Features of the Compressor

\begin{tabular}{|c|c|c|c|c|c|c|c|c|c|}
\hline Design of the Compressor & \multicolumn{4}{|c|}{ Hermetic (with Vertical Shaft) } & \multirow{2}{*}{\multicolumn{2}{|c|}{$\begin{array}{c}\text { Open Type (with } \\
\text { Horizontal Shaft) } \\
\text { FV }\end{array}$}} & \multicolumn{3}{|c|}{$\begin{array}{l}\text { Semi-Hermetic Sealed } \\
\text { (with Horizontal Shaft) }\end{array}$} \\
\hline Type of compressor & \multicolumn{2}{|c|}{ HR } & \multicolumn{2}{|c|}{$\mathrm{HF}$} & & & \multicolumn{3}{|c|}{ FUBS } \\
\hline The piston stroke, $\mathrm{mm}$ & \multicolumn{2}{|c|}{32} & \multicolumn{2}{|c|}{38} & \multicolumn{2}{|c|}{50} & \multirow{2}{*}{\multicolumn{3}{|c|}{$\begin{array}{c}50 \\
67.5\end{array}$}} \\
\hline Cylinder diameter & \multirow{2}{*}{\multicolumn{2}{|c|}{$\frac{42}{48}$}} & \multirow{2}{*}{\multicolumn{2}{|c|}{$\begin{array}{l}50 \\
24\end{array}$}} & \multicolumn{2}{|c|}{67.5} & & & \\
\hline Frequency of rotation, s-1 & & & & & 10.5 & 24 & 24 & 16 & 24 \\
\hline Number of cylinders & 2 & 4 & 2 & 4 & 2 & 2 & 4 & 8 & 8 \\
\hline $\begin{array}{l}\text { Cooling capacity, } \mathrm{kW} \\
\mathrm{R} 12, t_{0}=-15^{\circ} \mathrm{C}, t_{\mathrm{k}}=30^{\circ} \mathrm{C} \\
\mathrm{R} 22, t_{0}=5^{\circ} \mathrm{C}, t_{\mathrm{k}}=40^{\circ} \mathrm{C}\end{array}$ & $\begin{array}{c}3.7 \\
11.8\end{array}$ & $\begin{array}{c}7.4 \\
23.6\end{array}$ & $\begin{array}{l}3.2 \\
-\end{array}$ & $\begin{array}{c}6.4 \\
-\end{array}$ & $\begin{array}{l}3.5 \\
-\end{array}$ & $\begin{array}{c}6.9 \\
-\end{array}$ & $\begin{array}{c}13.9 \\
-\end{array}$ & 20.9 & $\begin{array}{c}29.0 \\
-\end{array}$ \\
\hline $\begin{array}{l}\text { Watt consumption (Under the same conditions), } \mathrm{kW} \\
\text { R12 } \\
\text { R22 }\end{array}$ & $\begin{array}{l}1.7 \\
3.9\end{array}$ & $\begin{array}{l}3.4 \\
7.8\end{array}$ & $\begin{array}{l}1.6 \\
-\end{array}$ & $\begin{array}{l}3.2 \\
-\end{array}$ & $\begin{array}{l}1.7 \\
-\end{array}$ & $\begin{array}{c}2.5 \\
-\end{array}$ & $\begin{array}{l}4.9 \\
-\end{array}$ & $\begin{array}{l}7.2 \\
-\end{array}$ & $\begin{array}{c}10.0 \\
-\end{array}$ \\
\hline Lubricant & \multicolumn{2}{|c|}{ RF 22-24 } & \multicolumn{2}{|c|}{ RF 12-16 } & \multicolumn{2}{|c|}{ RF $12-16$} & \multicolumn{3}{|c|}{ RF 12-16 } \\
\hline The presence of piston rings & \multicolumn{4}{|c|}{ Without rings } & \multicolumn{5}{|c|}{ With rings } \\
\hline Type of the shaft & Crankshaft & Crankshaft & $\begin{array}{l}\text { Eccentric } \\
\text { shaft }\end{array}$ & Crankshaft & \multicolumn{5}{|c|}{ Crankshaft } \\
\hline The design of the connecting rod bearing & $\begin{array}{l}\text { Split with } \\
\text { bronze } \\
\text { bushing }\end{array}$ & $\begin{array}{l}\text { Split with } \\
\text { babbitt } \\
\text { bushing }\end{array}$ & $\begin{array}{l}\text { One-piece } \\
\text { with bronze } \\
\text { bushing }\end{array}$ & $\begin{array}{l}\text { Split with } \\
\text { babbitt } \\
\text { bushing }\end{array}$ & \multicolumn{2}{|c|}{$\begin{array}{l}\text { Split with babbitt } \\
\text { shell lining }\end{array}$} & \multicolumn{3}{|c|}{ Split with babbittbushing } \\
\hline Pin fit in the piston & Transitional & \multicolumn{3}{|c|}{ With clearance } & \multicolumn{5}{|c|}{ Transitional } \\
\hline Type of main bearing & \multicolumn{4}{|c|}{ plain bearing } & \multicolumn{5}{|c|}{ rolling bearing } \\
\hline $\begin{array}{l}\text { Lubricating the connecting rod plain bearings and } \\
\text { support plain bearings }\end{array}$ & \multirow[t]{2}{*}{ forced } & \multicolumn{3}{|l|}{ forced } & \multicolumn{2}{|c|}{ by spraying } & \multirow{2}{*}{\multicolumn{3}{|c|}{ forced }} \\
\hline rod - pin fit & & by spraying & & & by spray & & & & \\
\hline
\end{tabular}

\begin{tabular}{|c|c|c|c|c|c|c|c|c|}
\hline \multirow{3}{*}{ Refrigerant } & \multirow{3}{*}{$\begin{array}{c}\text { Type of } \\
\text { Compressor }\end{array}$} & \multirow{3}{*}{$\begin{array}{l}\text { Number of } \\
\text { Cylinders }\end{array}$} & \multirow{3}{*}{$\begin{array}{c}\text { Number of Tested } \\
\text { Compressors }\end{array}$} & \multirow{2}{*}{\multicolumn{2}{|c|}{$\begin{array}{c}\text { Operating Mode, } \\
{ }^{\circ} \mathrm{C}\end{array}$}} & \multirow{3}{*}{$\begin{array}{c}\text { Lubricating } \\
\text { Oil }\end{array}$} & \multicolumn{2}{|c|}{ Total Operating Time, $\mathrm{h}$} \\
\hline & & & & & & & In Continuous & In Cyclic \\
\hline & & & & $t_{0}$ & $t_{\mathrm{k}}$ & & Mode & Mode \\
\hline \multirow{15}{*}{$\mathrm{R} 12$} & \multirow{5}{*}{ HR } & \multirow{2}{*}{2} & 4 & -15 & 30 & RF 22-24 & - & 42000 \\
\hline & & & 2 & -15 & 30 & RF $12-16$ & - & 27000 \\
\hline & & \multirow{3}{*}{4} & 2 & $-25,5$ & 40 & RF 22-24 & 29100 & 5000 \\
\hline & & & 5 & -15 & 30 & RF 22-24 & 2700 & 16000 \\
\hline & & & 1 & -15 & 30 & RF $12-16$ & - & 6000 \\
\hline & \multirow{7}{*}{$\mathrm{FH}$} & \multirow{6}{*}{2} & \multirow{4}{*}{$\begin{array}{c}5 \\
\text { (Eccentric shaft) }\end{array}$} & -15 & 30 & \multirow{4}{*}{ RF $12-16$} & 7100 & 2200 \\
\hline & & & & 5 & 40 & & 17900 & 5300 \\
\hline & & & & -25 & 40 & & 4900 & - \\
\hline & & & & 3,10 & 65 & & 5100 & - \\
\hline & & & 2 & -15 & 50 & \multirow{2}{*}{ RF 12-16 } & 7100 & 7100 \\
\hline & & & (Crankshaft) & 5 & 50 & & 3000 & - \\
\hline & & 4 & 3 & 5 & 50 & RF 12-16 & 30000 & 15000 \\
\hline & \multirow{3}{*}{$\begin{array}{l}\text { FV } \\
\text { FUBS }\end{array}$} & 2 & $\begin{array}{c}2\left(f=24 s^{-1}\right) \\
2\left(f=10.5 s^{-1}\right)\end{array}$ & -15 & 30 & RF $12-16$ & - & $\begin{array}{c}2500 \\
51000\end{array}$ \\
\hline & & 4 & 3 & \multirow{2}{*}{$\begin{array}{c}5 \\
5 \\
-15,10,0\end{array}$} & \multirow[b]{2}{*}{$\begin{array}{l}40 \\
60\end{array}$} & \multirow[b]{2}{*}{ RF 12-16 } & 35000 & - \\
\hline & & 8 & $\begin{array}{l}1\left(f=24 s^{-1}\right) \\
1\left(f=16 s^{-1}\right)\end{array}$ & & & & - & 16500 \\
\hline \multirow{2}{*}{$\mathrm{R} 22$} & \multirow{2}{*}{$\mathrm{HR}$} & 2 & 2 & \multirow{2}{*}{5} & \multirow{2}{*}{40,50} & \multirow{2}{*}{ RF 22-24 } & \multirow{2}{*}{16060} & \multirow{2}{*}{-} \\
\hline & & 4 & 1 & & & & & \\
\hline \multirow{2}{*}{ R502 } & \multirow{2}{*}{$\mathrm{HR}$} & \multirow{2}{*}{2} & \multirow[t]{2}{*}{1} & -15 & 30,40 & \multirow{2}{*}{ RF 22-24 } & 1000 & - \\
\hline & & & & -25 & 40 & & 950 & 680 \\
\hline
\end{tabular}

\section{RESULT AND DISCUSSIONS}

When comparing the wear resistance of friction surfaces of the compressors parts, the following transactions were used:

- An average rate of wear, $\mu \mathrm{m} / 1000$ hours.

$C=2 h_{i} / \tau_{i}$

where $h_{i}$ - linear wear of the surface during the i time interval, $\mu \mathrm{m}$

$\tau_{i}$ - i time interval, 1000hours

- An average rate of clearance growth in the fits, $\mu \mathrm{m} / 1000$ hours

$C_{s}=C_{1}+C_{2}$

where $C_{1}, C_{2}$ - the wear velocity of the first and second parts of the fit respectively, $\mu \mathrm{m} / 1000$ hours 
- Intensity of wear of the parts

$I=h_{i} / L_{T i}$

where $L_{T i}$ - friction distance during the i time interval, $\mu \mathrm{m}$

- The total intensity of wear of the parts of the fit

$I_{s}=I_{1}+I_{2}$

where $I_{1}, I_{2}$ - an intensity of wear of the first and second parts of the fit respectively

The comparison is made between these standards on cross-sections and maximum levels of wear of the friction surfaces in two periods, startup operation wear and constant operation wear. For values of $C$ and $C S$ has been compared to the wear resistance of the same pieces in different compressors and equal piston stroke as well as the frequency of the spindle. On the other hand for the values, I and IS has been compared for different piston steps as well as the rotational frequency of the spindle.

As a basis for comparing the wear of different parts for different types of compressors, we took test data of two cylinder compressors with the refrigerant R12 and oil lubrication RF 12-16 (in the standard conditions) as well as the refrigerant R22 and oil lubrication RF 22-24 (in the high-temperature system, the boiling temperature $\mathrm{t}_{\mathrm{o}}=5^{\circ} \mathrm{C}$, the degree of condensation $t_{k}=40^{\circ} \mathrm{C}$ ) with basic data and it have been compared to the wear of compressor parts with other design parameter values as well as when they run at different conditions (regular or continuous operation, cyclic recurrence) and for another refrigerant R502. Table 3 shows the rate of wear for parts of two- cylinder compressors that work on the refrigerants R12 and R22 and R502. The linear wear $h$ of the surface of friction parts of the two-cylinder compressors on the path of friction $L_{T}$ and dependence of the intensity of wear $I$ of the friction surfaces on the average specific pressure $p$ in the cylinder - piston fit, are shown in Figure 1 and Figure 2 respectively.

Table 3: The Average Rate of Wear in Parts of Two-Cylinder Compressors

\begin{tabular}{|c|c|c|c|c|c|c|c|}
\hline \multirow{4}{*}{ fit } & \multicolumn{7}{|c|}{ The Average Rate of Wear $(\mu \mathrm{m} / 1000$ hours $)$} \\
\hline & \multicolumn{5}{|c|}{ R12 } & \multirow{3}{*}{$\begin{array}{l}\text { R22 } \\
\text { HR }\end{array}$} & \multirow{3}{*}{$\begin{array}{c}\text { R502 } \\
\text { HR }\end{array}$} \\
\hline & \multirow{2}{*}{ HR } & \multicolumn{2}{|c|}{ FH } & \multicolumn{2}{|c|}{ FV } & & \\
\hline & & Crank shaft & Eccentric haft & $f=10.5 s^{-1}$ & $f=24 s^{-1}$ & & \\
\hline Cylinder - piston & 0,43 & \multicolumn{2}{|c|}{1,35} & 0,94 & 1.92 & 0,89 & 0,96 \\
\hline (compression ring - & 0,28 & \multicolumn{2}{|c|}{0,75} & 0,70 & 1,55 & 0,73 & 0,80 \\
\hline by radial thickness) & - & \multicolumn{2}{|c|}{-} & $(9,00)$ & $(12,00)$ & - & - \\
\hline Connecting rod - & 0,37 & \multirow{2}{*}{\multicolumn{2}{|c|}{$\begin{array}{l}0,40 \\
2,43 \\
\end{array}$}} & 0,42 & 0,76 & 0,41 & 0,46 \\
\hline piston pin & 1,01 & & & 0,84 & 1,24 & 1,17 & 1,33 \\
\hline Piston - niston nin & 0,46 & \multirow{2}{*}{\multicolumn{2}{|c|}{$\begin{array}{l}0,88 \\
3,12\end{array}$}} & 0,49 & 0,73 & 0,81 & 0,76 \\
\hline \multirow{3}{*}{$\begin{array}{l}\text { Connecting rod - } \\
\text { shaft }\end{array}$} & 0,69 & & & 0,89 & 0,92 & 0,90 & 0,97 \\
\hline & 074 & 1,92 & 1,12 & 0,54 & 1,37 & & 139 \\
\hline & 0,14 & 0,76 & 1,43 & 0,27 & 0,59 & 1,18 & 1,39 \\
\hline \multirow{2}{*}{$\begin{array}{l}\text { Upper support - } \\
\text { shaft }\end{array}$} & 0,33 & 0,32 & 0,51 & - & - & 0,98 & 1,02 \\
\hline & 0,46 & 0,81 & 2,08 & - & - & 0,65 & 0,59 \\
\hline \multirow{2}{*}{$\begin{array}{l}\text { Lower support - } \\
\text { shaft }\end{array}$} & 0,35 & 0,69 & 1,00 & - & - & 0,50 & 0,42 \\
\hline & 0,56 & 1,12 & 1,24 & - & - & 0,67 & 0,61 \\
\hline
\end{tabular}




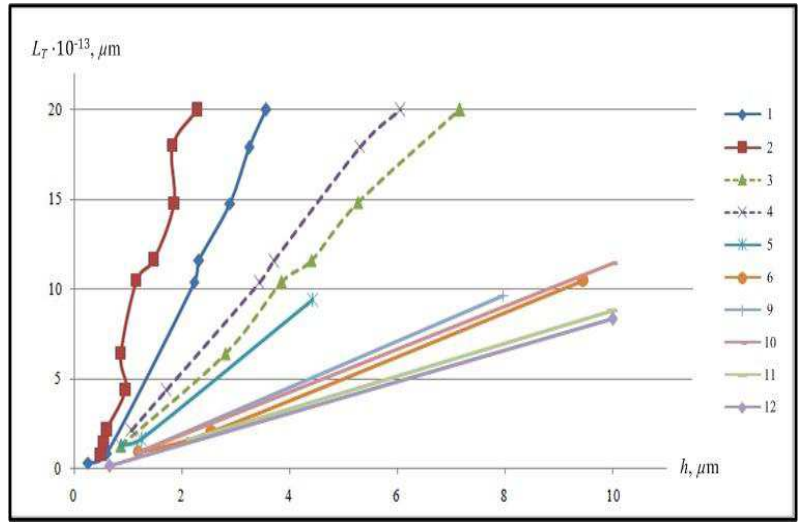

(a): Cylinder - Piston Fit

$(1,3,5,9,10$ - cylinder, 2, 4, 6, 11, 12- piston)

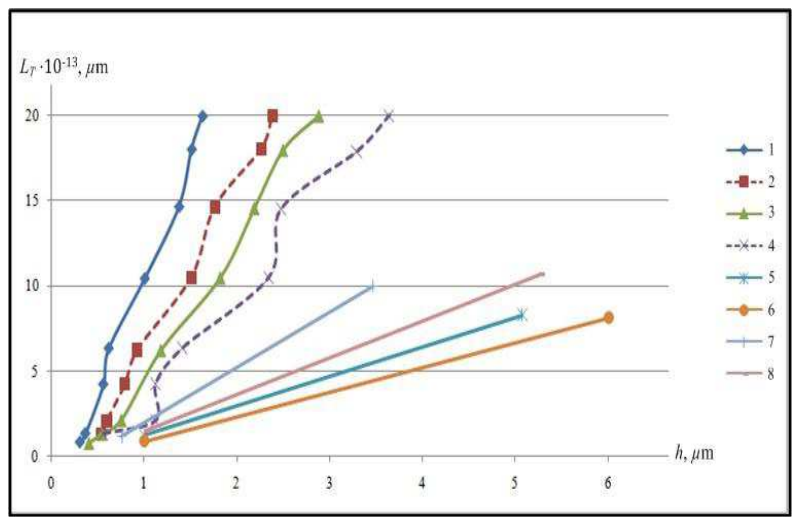

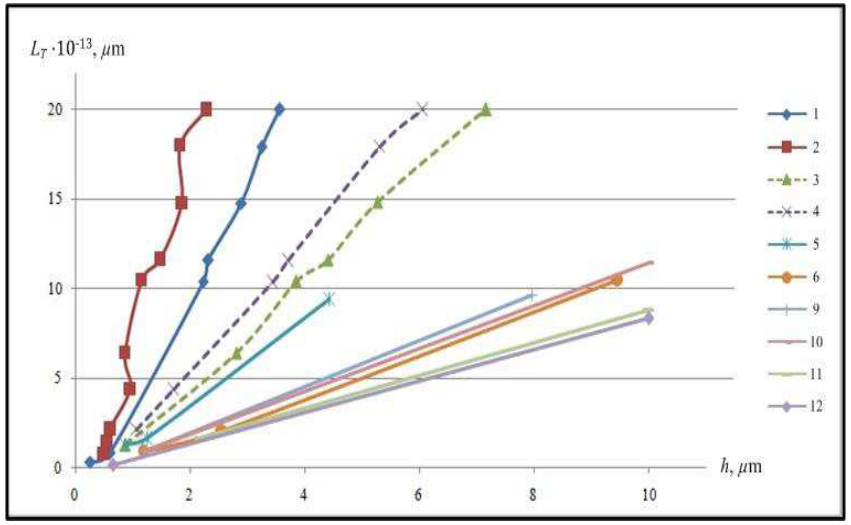

(b): Connecting Rod - Shaft Fit $(1,2,5,8,10,12$ - connecting rod, $3,4,6,7,9,11$ - shaft)

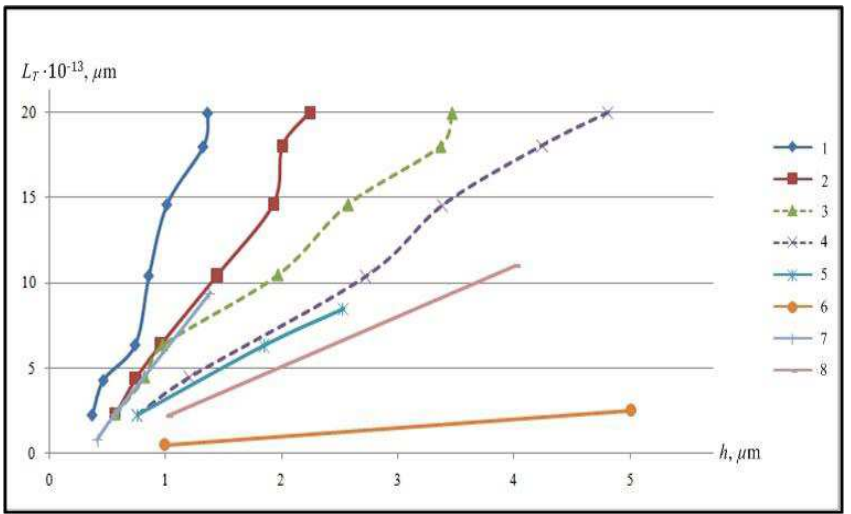

Source: 1, 2, 3, 4- Compressor Type HR; 5, 6, 7, 8- Compressor Type FH (5, 6- Eccentric Haft);

9, 10, 11, 12- Compressor Type FV (11, 12- Low Speed);

- R12, - - - - - R22.

(c): Lower Support - Shaft Fit

(d): Upper Support - Shaft Fit

(1, 3, 5, 7- lower support, 2, 4, 6, 8- shaft)

$(1,3,5,7$ - upper support, 2, 4, 6, 8-shaft)

Figure 1: Dependence of Linear Wear $h$ of the Surface of Friction Parts of the Two-Cylinder Compressors on Path of Friction LT

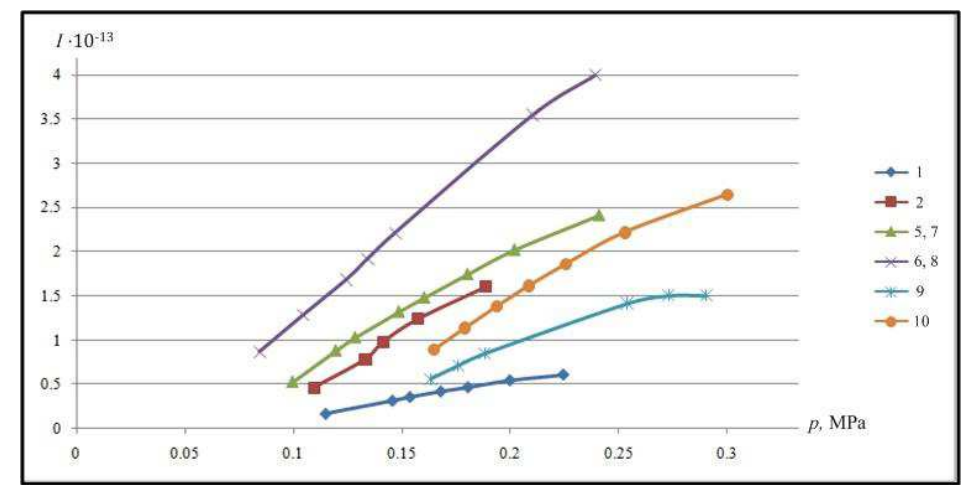

Source: 1, 2- compressor type HR; 5, 6, 7, 8- compressor type FH; 9, 10- compressor type FV, FUBS; 2, 6, 8, 10- cylinder; 1, 5, 7, 9- piston

Figure 2: Dependence of Intensity of Wear $I$ of the Friction Surfaces on the Average Specific Pressure $p$ in the Cylinder - Piston Fit, when Working on the Refrigerant R12 


\section{Cylinder - Piston}

In this fit, the highest wear resistance of the friction surfaces in the compressor type HR is $C_{s}=0.71 \mu \mathrm{m} / 1000$ hours $I_{S}=0.27 \cdot 10^{-13}$, regardless of the larger-speed sliding in the two pieces $(2.96 \mathrm{~m} / \mathrm{s})$. Because of the relatively high pressure in the fit when their work using refrigerant R22, the severity of the wear in fit parts of compressors HR increased more than twice. The lowest wear resistance is in compressors FV piston manufacturer of cast iron rings when rotational frequency $24 \mathrm{~s}^{-1}$ is $C_{s}=3.74 \mu \mathrm{m} / 1000$ hours $I_{S}=2.41 \cdot 10^{-13}$.. In all cases when traditional cast iron assembly (for sleeve or liner) and aluminum alloy (for piston) be used the wear resistant in the piston is largest 2.1 to 4.1 times than in sleeve. The FH compressors of pistons manufactured from cast iron and sleeve or liner made from steel, the wear resistance of friction surfaces be in an intermediate state between HR compressors and compressors FUBS and when rotational frequency equal $24 \mathrm{~s}^{-1}$.

\section{Connecting Rod and Piston Pin}

Better wear resistance found to this fit parts in HR compressors that are close to the wear-resistant of in lowspeed compressors FV (Cs do not exceed $1.5 \mu \mathrm{m} / 1000$ hours which is lower by $30 \%$ than in the high-speed compressors FUBS and FV). Wear resistance of piston-pin is least 1.5 to 2 times than bronze bushing of the top head of the connection arm (piston attaching end or small end. This means that this recital applies to all types of compressors.

In all types of closed compressors with a spindle status vertical (and horizontal cylinders status), the wear resistant of piston pin relatively low, which can be explained by the weak warming of lubricating oil on the friction surfaces of the associated vertically. While in compressors FH (piston-pin connected while ensuring clearance) and for throwing lubricating oil in the event of strikes, recorded less resistant to wear in piston-pin, speed equal to $(2.43 \mu \mathrm{m} / 1000 \mathrm{hours})$.

\section{Piston and Piston Pin}

Wear resistance in these HR compressors convergent with the FV compressors and FUBS and increase more than two and a half times than in compressors FH. The wear-resistant in piston pin less than the wear resistance in piston boss in all types of compressors, regardless of the piston material (steel, Aluminum alloy or cast iron). When working on the refrigerant (R22), the wear resistance for HR compressors decreases by almost 1.5 times $(\mathrm{Cs}=1.71 \mu \mathrm{m} / 1000 \mathrm{hours})$. The low wear resistance in this fit in compressors FH is caused by the clearance development between piston-pin and piston boss, as well as the worst conditions of lubrication.

\section{Connecting Rod and Shaft}

The wear resistance in friction parts of this fit in HR compressors is the same as in compressors FUBS and FV and $\mathrm{FH}$ of the eccentric shaft and equal to $I_{S}=0.78 \cdot 10^{-13}$.

A traditional combination of materials, Babbitt alloy for connecting arm and steel for the column in compressors FUBS and FV and FH of the crankshaft ensures wear resistance two times larger than the connecting arm. When you use a combination of materials in the steel- bronze in compressors HR and FH of the eccentric shaft and regardless of the user bronze type we note the opposite image: wear resistance is lower than in the connecting arm. When there lining Babbitt bushing in the FUBS's compressor of eight cylinders when frequency equal to $16 \mathrm{~s}^{-1}, 24 \mathrm{~s}^{-1}$ Regardless of the availability of better lubrication conditions ( forced lubrication), the wear resistance of friction pair are the same as in a pair of friction delivery arm of manufactured from Babbitt alloy. 


\section{Upper Support and Shaft and Lower Support and Shaft}

Wear resistance for both friction parts in the compressor HR almost the same $I_{s} \approx 0.22 \cdot 10^{-13}$ and more than three times greater than in compressors FH for the eccentric shaft as with the crankshaft. This is a result of the fact that the specific pressure lower by about three times in this fits.

\section{CONCLUSIONS}

As a result of analysis of wear resistance for reciprocating compressors that are used in small refrigerating machines, it has been identified a number of features and public foundations.

- The severity of the wear friction at the beginning of the operation phase is much higher than in the operation phase (steady state) by $8-18$ times.

- The severity of the wear friction is mainly dependent on the relative pressure in the fit (Figure 2). The impact of the relative speed of sliding pieces on the severity of the wear it is significantly lower.

- Pieces in the compressors of the same type when the work of these compressors on medium-temperature system or on high-temperature system and due to the convergence of the relative pressure in the fit in both cases, they practically have the same wear resistance, while when work on a low-temperature system, the corrosion resistance reduced by $25-40 \%$.

- All types of closed compressors of vertical column design are characterized by twice the wear resistance of piston pin, which is explained by the weakness of the ability of this design to keep lubricating oil on fit surfaces.

- When choosing the materials transportation arm from babbitt alloy and spindle from steel, wear resistance ensures greater in the spindle of them in the delivery of bronze arm and spindle combination of steel.

- The wear friction in a fit of compressors, four-cylinder, and eight-cylinder, are less resistance by between $15-25 \%$ of them in compressors with two-cylinder. That could explain the terms of lubricating the worst heat and stress that originates in the parts of multi-cylinder compressors.

- The wear resistance for HR compressors when work on the refrigerant (R502) is the same when working on the refrigerant (R22).

\section{REFERENCES}

1. Hoerbi Gartmann, H., (1970), De Laval Engineering Handbook, Compiled by the engineering staff of De Laval Turbine, Inc., McGraw-Hill Book Company, New York, 1970.

2. Noall, M. and Couch, W., (2003), "Performance and Endurance Tests of Six Mainline Compressor Valves in Natural Gas Compression Service," Gas Machinery Conference Paper, 2003.

3. Y. X. Zhang, L. J. Chen, B. B. Li, "Fault Analysis on Crosshead Fracture of the Reciprocating Piston Compressor C102B", Advanced Materials Research, Vols. 189-193, pp. 1188-1193, 2011.

4. Mahmood, I., Jameel, W. W., \& Khaleel, L. A. (2013). Improved oxidation resistance for thermal barrier ceramic coating project. Int. J. Res. Eng. \& Technol, 1(1).

5. A.T. Prata, J.R. Barbosa Jr., Role of the thermodynamics, heat transfer and fluid mechanics of lubricant oil in hermetic 
reciprocating compressors, Heat Transfer Engineering 30 (7) (2009) 533-548.

6. Exel, A. N. and Lilie, D. E. B., "Evaluation of Lubrication Between Piston and Cylinder of Reciprocating Compressors by Electrical Instrumentation" (1994). International Compressor Engineering Conference.

7. Taur, P. G., \& Sonawane, S. A. Analysis Of Wear Resistance Of Tool Steel After Deep Cryogenic Treatment.

8. Kim, J. W.; Kim, S. S.; Joung, S. H.; Huh, Y. J.; and Lee, J., "Performance Analysis for the Development of Hermetic Reciprocating Compressor Using HC600a" (1998). International Compressor Engineering Conference. 